\title{
Inhibitory effects of Rubi Fructus extracts on hepatic steatosis development in high-fat diet-induced obese mice
}

\author{
MI KYUNG NAM ${ }^{1}$, HYE RAN CHOI ${ }^{1}$, JIN SOOK CHO ${ }^{2}$, SOO MIN CHO ${ }^{1}, \mathrm{KI} \mathrm{CHAN} \mathrm{HA}^{3}$, \\ TAE-HYEON KIM ${ }^{4}$, HEE-YOUNG RYU ${ }^{1}$ and YOUNG-IK LEE ${ }^{1,2}$ \\ ${ }^{1}$ Industrial Bioresource Research Center, Korea Research Institute of Bioscience and Biotechnology, Daejeon 305-606;
${ }^{2}$ Lee's Biotech Co., Daejeon 305-806; ${ }^{3}$ Healthcare Claims and Management Incorp., Jeonju, Chonbuk 949-14;
Department of Gastroenterology, Wonkwang University School of Medicine, Iksan, Chonbuk 500-711, Republic of Korea
}

Received June 28, 2013; Accepted February 10, 2014

DOI: $10.3892 / \mathrm{mmr} .2014 .2398$

\begin{abstract}
The present study was performed to investigate the potential effects of the unripened dried fruit of Rubus coreanus Miq., Rubi Fructus (RF), on hepatic steatosis and lipid metabolism in mice fed with a high-fat diet (HFD) known to induce obesity and hyperlipidaemia. Rubi Fructus extract (RFex) fed mice demonstrated a reduced body weight and adipose tissue weight. RFex fed mice also demonstrated decreased aminotransferase levels, lipid contents [triglyceride (TG), total cholesterol (TC) and low-density lipoprotein-cholesterol (LDL-C)], leptin content and increased high-density lipoprotein-cholesterol (HDL-C) contents in the plasma. These effects were accompanied by a decreased expression of lipogenic genes, including sterol regulatory element binding protein-1c, liver $\mathrm{X}$ receptor, fatty acid synthase (FAS), acetyl-CoA carboxylase, cluster of differentiation 36, lipoprotein lipase and decreased lipogenic enzyme FAS and 3-hydroxy-3 methylglutamyl coenzyme reductase enzyme activities, while elevating carnitine palmitoyltrasferase-1 activity. Based on these results, the present study hypothesized that the inhibitory effect on hepatic steatosis of RFex is the result of the suppression of lipid synthesis in mice fed with HFD, suggesting that RFex may be beneficial in preventing hepatic steatosis and liver lipotoxicity.
\end{abstract}

\section{Introduction}

Nonalcoholic fatty liver disease (NAFLD) is the most common cause of chronic liver disease, which includes a spectrum of liver diseases from hepatic steatosis to nonalcoholic steatohepatitis (1-3), where the latter is known to increase

Correspondence to: Dr Young-Ik Lee, Industrial Bioresource Research Center, KRIBB, 125 Gwahakro, Daejeon 305-606, Republic of Korea

E-mail: yilee@kribb.re.kr

Key words: Rubi Fructus, high-fat diet, hepatic steatosis, lipogenic gene, lipogenic enzyme, liver lipotoxicity the risk of liver cirrhosis and hepatocellular carcinoma (4). NAFLD is associated with metabolic syndrome, consisting of obesity, diabetes, hyperlipidemia and insulin resistance (5). As a form of NAFLD, hepatic steatosis results from the accumulation of fat in the liver, primarily through excessive transport of free fatty acids from visceral adipose tissue into the liver and from an imbalance in de novo lipid synthesis and catabolism in hepatocytes (6-8). The prolonged energy imbalance increases the amount of triglyceride (TG) content in adipose tissue and these TGs are stored as lipid droplets in the liver. Thus, hepatic steatosis is generally characterized by excess hepatic lipid accumulation as esterified TG in the liver. Cellular toxicity mediated by this excess hepatic lipid accumulation known as lipotoxicity, has been implicated in the pathophysiology of insulin resistance, type 2 diabetes and metabolic syndrome (9).

Several agents are known to improve NAFLD histologically or biochemically in animals and humans (10), although, numerous side effects have been reported (11).

Rubus coreanus is one of the 100 genera in the family Rosaceae, subfamily Rosoideae, and there are currently 250 species of Rubus established around the world. The dried unripe fruit of Rubus coreanus Miq. Rubi Fructus (RF) has been used as a traditional oriental medicine in Asia, including Korea and China (12-14). RF has been used for the management of impotence and spermatorrhea, and as a stomachic and tonic in Korea (15-17), and it has been identified that RF exhibits a hepatoprotective effect in animal models $(18,19)$. Ellagic acid from RF protects hepatocytes from damage by inhibiting mitohondrial production of reactive oxygen species (20), while the same flavonoid inhibits host immune tolerance induced by the hepatitis B virus-e antigen (21). Ellagic acid has also been reported to affect cellular lipid metabolism during benzoyl peroxide-induced toxicity and effectively reduced the elevations of plasma cholesterol in hyperlipidemic rabbits (22).

The present study examined the effects of the Rubi Fructus extract (RFex) containing ellagic acid on the development and progression of hepatic steatosis and liver lipotoxicity in mice fed with a high-fat diet (HFD) by assessing hepatic lipid accumulation, the mRNA expression of lipogenic genes and enzyme activities. 


\section{Materials and methods}

Plant materials and the preparation of extracts. The unripened fruit of RF was collected during June from Buan (Chunra, Korea). The plant samples were kept in the herbarium of the Korea Research Institute of Bioscience and Biotechnology (KRIBB). The RFex containing ellagic acid was prepared by Lee's Biotech Co., Ltd. (Yuseonggu, Daejeon, Korea).

Animal treatment. The male C57BL/6 mice were obtained from Koatech Technology Corporation (Seoul, Korea). The animals were allowed free access to rodent food (Purina Co., Seoul, Korea) and tap water and maintained in a controlled environment at $22^{\circ} \mathrm{C}$ and $50 \pm 10 \%$ relative humidity with a 12 -h dark/light cycle, and acclimatized for at least one week prior to use. The mice were randomly divided into three groups: the normal diet (ND), high-fat diet (HFD) and HFD + RFex $(100 \mathrm{mg} / \mathrm{kg})$ fed group. The HFD was based on the diet from Open Source Diet (Central Animal Lab Inc., Seoul, Korea) containing $60 \% \mathrm{kcal}$ fat, while the ND contained $10 \% \mathrm{kcal}$ fat. The diets were administered for 10 weeks and the weight gain was measured once a week. Food intake was measured for three consecutive days per week by subtraction of food jar pre-and post-weights for 10 weeks. At necropsy, the sides of the epididymal, retroperitoneal and perirenal adipose tissues were removed and weighed, and the relative adipose tissue weight to body weight ratio was calculated.

All animal experiments were approved by the Institutional Animal Care and Use Committee and Ethics Committee, which were performed in accordance with the institutional guidelines at the KRIBB (Daejeon, Korea).

Plasma, hepatic lipid concentrations and liver histology. Following 10 weeks of RFex administration, blood samples were collected by a heart puncture method to determine the levels of plasma enzymes [alanine aminotransferase (ALT) and aspartate aminotransferase (AST)], plasma TG and total cholesterol (TC). The plasma was prepared by the centrifugation of blood $\left(10,000 \times \mathrm{g}\right.$ for $5 \mathrm{~min}$ at $\left.4^{\circ} \mathrm{C}\right)$ and stored at $-70^{\circ} \mathrm{C}$ until analysis. Plasma ALT and AST levels were measured using an automatic biochemical analyzer in the Animal Experiment Laboratory at the KRIBB. Plasma TG and TC levels were measured directly with a BCS analysis kit (Bioclinical System Co., Anyang, Korea). Plasma leptin was determined by the sandwich ELISA method using a commercially available rat leptin kit according to the manufacturer's instructions (Bioclinical System Co., Anyang, Korea). Immediately following sacrification of the mice, half of the liver was removed, quickly frozen in liquid nitrogen and stored at $-70^{\circ} \mathrm{C}$. Hepatic lipids were extracted using the modified procedure of the Folch method (23). Briefly, frozen liver tissue was homogenized in $0.9 \% \mathrm{NaCl}$ solution and chloroform - methanol, $1: 2 \mathrm{v} / \mathrm{v}$ was added to the homogenate. Then the mixture was vortexed and centrifuged (2,000 x g for $20 \mathrm{~min})$, and the upper phase was aspirated and filtered. The collected chloroform phase was used for analysis. Hepatic TG and TC concentrations were analyzed using an enzymatic analysis kit (BCS analysis kit; Asan Pharmaceutical Co. Ltd., Seoul, Korea).

The remaining half of the liver was removed and immediately fixed in a buffer solution of $10 \%$ formalin for pathological analysis. Fixed tissues were processed routinely for paraffin embedding and $5 \mu \mathrm{m}$ sections were prepared and stained with haematoxylin and eosin. Stained areas were viewed using an optical microscope.

Quantitative polymerase chain reaction (qPCR) analysis for hepatic lipogenic gene expression. Total RNA from the liver was isolated and the samples were reverse-transcribed using the TOPscript $^{\mathrm{TM}}$ cDNA synthesis kit (Enzynomics, Seoul, Korea). The resulting cDNA was amplified using a PCR system (Astec, Fukuoka, Japan) and the Premix Taq (Bioneer, Daejeon, Korea) according to the manufacturer's instructions. The sequences of oligonucleotides used as primers were designed using Primer Express 3.0 (Applied Biosystems, Carlsbad, CA, USA). The sequences are listed in Table I. All primer sets produced amplicons of the expected size and their identity was also verified by sequencing. The cycling conditions were $95^{\circ} \mathrm{C}$ for $10 \mathrm{~min}$, followed by 50 cycles of $95^{\circ} \mathrm{C}$ for $10 \mathrm{sec}$ and $60^{\circ} \mathrm{C}$ for $1 \mathrm{~min}$. The results were normalized against GAPDH and are presented as fold changes versus the reference gene.

Measurement of hepatic lipid-regulating enzyme activity. Hepatic enzymes were prepared according to the method of Hulcher and Oleson (24) with a slight modification. A homogenate was prepared in a buffer containing $0.1 \mathrm{~mol} / \mathrm{l}$ of triethanolamine, $0.02 \mathrm{~mol} / \mathrm{l}$ of EDTA and $2 \mathrm{mmol} / \mathrm{l}$ of dithiothreitol ( $\mathrm{pH}$ 7.0). The homogenate was centrifuged ( $600 \mathrm{x} \mathrm{g}$ for $10 \mathrm{~min}$ ) to remove any cell debris and the supernatant was again centrifuged $(10,000 \mathrm{x}$ g, followed by $12,000 \mathrm{x} \mathrm{g}$ for $20 \mathrm{~min}$ at $4^{\circ} \mathrm{C}$ ) to remove the mitochondrial pellet. The supernatant was then ultracentrifuged twice $\left(100,000 \mathrm{x}\right.$ g for $60 \mathrm{~min}$ at $\left.4^{\circ} \mathrm{C}\right)$ to remove the cytosolic supernatant. The mitochondrial and microsomal pellets were then redissolved in $800 \mu l$ of homogenization buffer and the protein content determined using the Bradford method using bovine serum albumin as the standard. Fatty acid synthase (FAS) activity was measured in the cytosolic fraction according to the method by Nepokroeff et al (7) by monitoring the malonyl-coenzyme A-dependent oxidation of nicotinamide adenine dinucleotide phosphate (NADPH) at $340 \mathrm{~nm}$, where the activity was represented by the oxidized NADPH nmol $/ \mathrm{min} / \mathrm{mg}$ protein. Carnitine palmitoyltrasferase-1 (CPT) activity was determined in the mitochondrial fraction according to the method by Markwell et al (25) and the results are expressed as $\mathrm{nmol} / \mathrm{min} / \mathrm{mg}$ protein. The activity of 3-hydroxy-3-methylglutaryl-coenzyme A (HMG-CoA) reductase was measured in microsomes based on a modification of the method of Hulcher and Oleson (24). The results are expressed as released CoA-SH $\mathrm{nmol} / \mathrm{min} / \mathrm{mg}$ protein.

Statistical analysis. All values from in vivo $(\mathrm{n}=6)$ and in vitro $(n=3)$ experiments are expressed as the mean \pm standard deviation. One-way analysis of variance and Duncan's test were used for multiple comparisons (SPSS, version 10.0; SPSS, Inc., Chicago, IL, USA). $\mathrm{P}<0.05$ was considered to indicate a statistically significant difference.

\section{Results}

Effects of RFex on body weight, total liver, adipose tissue weight and hepatic enzyme activities in HFD fed mice. The body weight increased with time in HFD groups, however, 
Table I. Nucleotide sequences of primers for qPCR of mRNA.

\begin{tabular}{|c|c|c|c|}
\hline Gene description & $\begin{array}{c}\text { Primer } \\
\text { sequences }\left(5^{\prime}-3^{\prime}\right)\end{array}$ & $\begin{array}{c}\text { Annealing } \\
\text { temperature }\left({ }^{\circ} \mathrm{C}\right)\end{array}$ & $\begin{array}{c}\text { PCR } \\
\text { product (bp) }\end{array}$ \\
\hline SREBP-1c & $\begin{array}{l}\text { F: GCCTGCTTGGCTCTTCTCTT } \\
\text { R: AGGTCAGCTTGTTTGCGATG }\end{array}$ & 55 & 102 \\
\hline $\mathrm{ACC} 1$ & $\begin{array}{l}\text { F: TGATGCAGAGGTACC } \\
\text { R: CGTAGTGGCCGTCT }\end{array}$ & 55 & 100 \\
\hline LPL & $\begin{array}{l}\text { F: TGCCGCTGTTTTGTTTTACC } \\
\text { R: TCACAGTTTCTGCTCCCAGC }\end{array}$ & 55 & 172 \\
\hline LXR & $\begin{array}{l}\text { F: ACAGCCAGACGCTACAACCA } \\
\text { R: TGGCGATAAGCAAGGCATAC }\end{array}$ & 55 & 193 \\
\hline CD36 & $\begin{array}{l}\text { F: TGACGTGGCAAAGAACAGC } \\
\text { R: GAAGGCTCAAAGATGGCTCC }\end{array}$ & 55 & 160 \\
\hline FAS & $\begin{array}{l}\text { F: CTGGCATTCGTGATGGAGTC } \\
\text { R: TGTTTCCCCTGAGCCATGTA }\end{array}$ & 55 & 101 \\
\hline GAPDH & $\begin{array}{l}\text { F: GGAGCCAAAAGGGTCATCAT } \\
\text { R: GTGATGGCATGGACTGTGGT }\end{array}$ & 60 & 321 \\
\hline
\end{tabular}

SREBP-1c, sterol regulatory element binding protein-1c; LPL, lipoprotein lipase; LXR, liver X receptor; CD36, cluster of differentiation 36; FAS, fatty acid synthase; ACC1, acetyl-CoA carboxylase 1; qPCR, quantitative polymerase chain reaction.

it decreased significantly in the HFD + RFex group $(\mathrm{P}<0.01$; Fig. 1A). The adipose tissue ratio also decreased significantly in HFD + RFex fed mice (Fig. 1B). A significant decrease in epididymal $(\mathrm{P}<0.01)$, retroperitoneal and perirenal weight to body weight was identified in the RFex fed group.

The total liver weight decreased significantly in RFex fed HFD mice compared with the HFD mice ( $\mathrm{P}<0.01$; Fig. $2 \mathrm{~A})$. The HFD fed group had elevated ALT and AST levels compared with the ND group $(\mathrm{P}<0.05$; Fig. 2B), while RFex treatment significantly attenuated HFD-induced ALT and AST levels $(\mathrm{P}<0.01$ and $\mathrm{P}<0.05$, respectively). RFex reversed the increase in ALT and AST, suggesting that it has the potential to prevent liver injury.

Effects of RFex on lipid profiles, free fatty acid levels and fatty droplet accumulations in the livers of HFD fed mice. To analyze the possible role of RFex in lipid metabolism, which is the key factor relative to fatty liver formation, plasma lipid profiles in experimental mice were investigated and are presented in (Table II).

The mice exposed to HFD exhibited increased TC (by 14\%), TG (by 59\%) and low-density lipoprotein-cholesterol (LDL-C; by $22.9 \%$ ) levels and decreased high-density lipoprotein-cholesterol (HDL-C; by $11 \%$ ) levels in the respective animal groups compared with the ND fed mice.

However, RFex feeding attenuated the serum lipid profile, which manifested in a reduced TC, TG and LDL-C concentration and a increased HDL-C levels as compared with the HFD group $(\mathrm{P}<0.05)$. As shown in Fig. 3A, the increase of liver TG and TC in the HFD group $(\mathrm{P}<0.01$ and $\mathrm{P}<0.05)$ was significantly suppressed by RFex $(\mathrm{P}<0.05)$.

Representative photomicrographs of liver histology are shown in Fig. 3B. HFD fed control mice demonstrated a high accumulation of microvesicular-type fat in the cytoplasm of the hepatocytes and demonstrated focal hepatitis characterized by scattered inflammatory cells and/or inflammatory foci. Treatment with RFex significantly improved the microvesicular hepatic steatosis (Fig. 3B; HFD + RFex) and liver histology results were almost the same as those of the ND (Fig. 3B; ND). These data clearly suggest that RFex is able to prevent hepatosteatosis via downregulating the accumulation of lipids in liver cells.

Effects of RFex on plasma leptin levels in mice. Leptin levels in the plasma were examined to assess the role of RFex in the prevention of obesity when the mice were fed a HFD (Fig. 4). There was a significant elevation in the levels of plasma leptin in the HFD (by 44\%) group compared with that of the ND group $(\mathrm{P}<0.05)$. In addition, the results implied that obesity in mice is accompanied with leptin resistance. However, the leptin concentration was significantly reduced in the RFex groups following 10 weeks of exposure to a HFD.

Effects of RFex on hepatic lipid regulatory gene expression in mice. To investigate the underlying mechanism responsible for the inhibitory effect of RFex on HFD-induced hepatic steatosis, hepatic expression levels of lipogenesis-regulating genes were determined, including liver $X$ receptor (LXR), sterol regulatory element binding protein-1c (SREBP-1c), acetyl-CoA carboxylase 1 (ACC1), cluster of differentiation 36 (CD36), lipoprotein lipase (LPL) and FAS. GAPDH was used as a control (Fig. 5). Compared with the HFD group, mice treated with RFex demonstrated significantly reduced mRNA expression of the tested genes $(\mathrm{P}<0.05, \mathrm{P}<0.01$ compared with the HFD-fed mice; Fig. 5A). The relative levels of specific mRNA levels are shown (Fig. 5B). 
Table II. Plasma lipid profiles from mice exposed to different experimental diets.

\begin{tabular}{lcccc}
\hline Group & $\begin{array}{c}\text { Total cholesterol } \\
(\mathrm{mg} / \mathrm{dl})\end{array}$ & $\begin{array}{c}\text { Triglycerides } \\
(\mathrm{mg} / \mathrm{dl})\end{array}$ & $\begin{array}{c}\text { HDL-cholesterol } \\
(\mathrm{mg} / \mathrm{dl})\end{array}$ & $\begin{array}{c}\text { LDL-cholesterol } \\
(\mathrm{mg} / \mathrm{dl})\end{array}$ \\
\hline ND & $112.4 \pm 3.3$ & $69.4 \pm 3.4$ & $97.4 \pm 4.0$ & $78.6 \pm 5.8$ \\
HFD & $128.6 \pm 3.2^{\mathrm{a}}$ & $110.8 \pm 19.4^{\mathrm{b}}$ & $101.0 \pm 2.1$ & $96.6 \pm 7.1^{\mathrm{a}}$ \\
HFD + RFex & $109.5 \pm 2.1^{\mathrm{c}}$ & $82.8 \pm 5.6^{\mathrm{c}}$ & $97.7 \pm 3.0$ & $74.3 \pm 4.5$ \\
\hline
\end{tabular}

Values in a column of lipid profiles demonstrated $\left({ }^{\mathrm{a}} \mathrm{P}<0.05,{ }^{\mathrm{b}} \mathrm{P}<0.01\right.$ and $\left.{ }^{\mathrm{c}} \mathrm{P}<0.05\right)$ different compounds to ND and HFD, respectively. ND, normal diet; HFD, high-fat diet; RFex, Rubi Fructus extract; HDL, high-density lipoprotein; LDL, low-density lipoprotein.

A

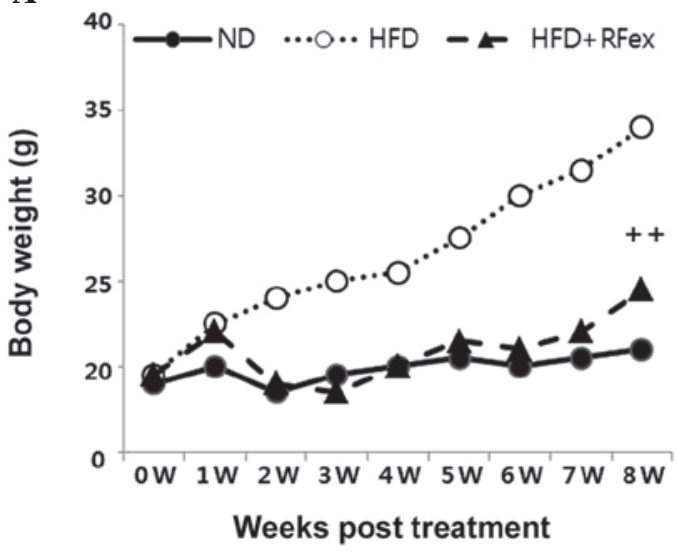

B

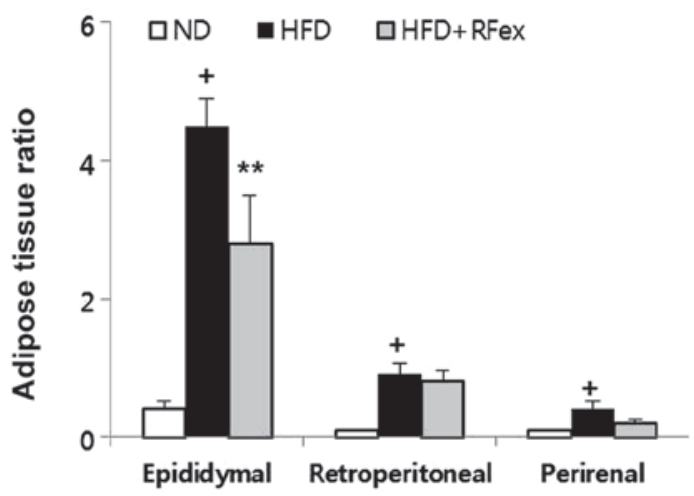

Figure 1. (A) Changes in body weight and (B) relative fat mass in C57BL/6 mice treated with a ND, HFD and HFD + RFex. For relative fat mass, relative adipose tissue weight to body weight was calculated. Values are expressed as the mean \pm standard deviation ( $\mathrm{n}=6$ for each group). ${ }^{+} \mathrm{P}<0.01 \mathrm{compared}$ with the control (ND) . $^{*} \mathrm{P}<0.01$ compared with HFD treatment. ND, normal diet; HFD, high-fat diet; RFex, Rubi Fructus extract.

A

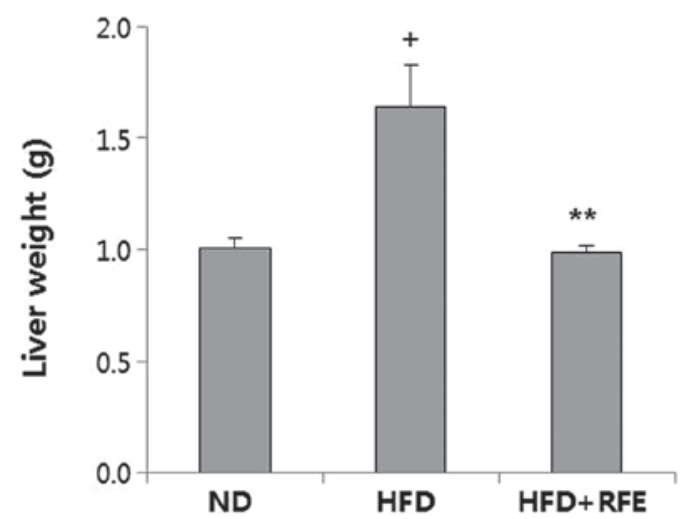

B

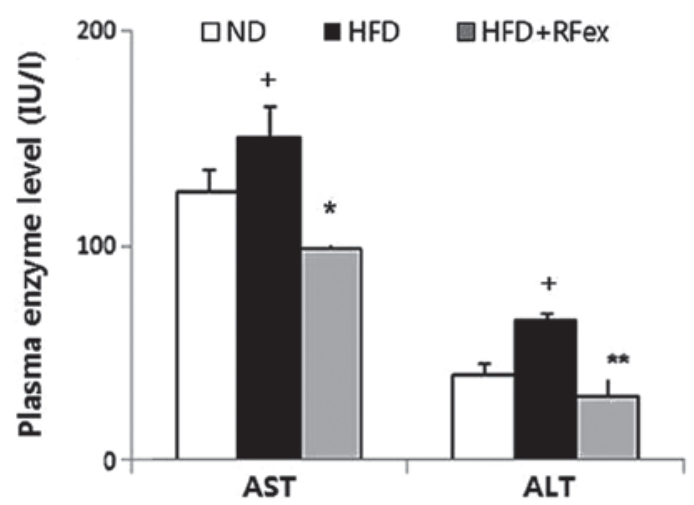

Figure 2. (A) Changes in liver weight and (B) serum ALT and AST activity in C57BL/6 mice treated with an ND, HFD and HFD + RFex. Each value represents the mean \pm standard deviation of six mice. ${ }^{+} \mathrm{P}<0.05$ compared with the control (ND). ${ }^{*} \mathrm{P}<0.05,{ }^{* *} \mathrm{P}<0.01$ compared with the HFD treatment. ALT, alanine aminotransferase; AST, aspartate aminotransferase; ND, normal diet; HFD, high-fat diet; RFex, Rubi Fructus extract.

Effects of RFex on hepatic lipid-regulating enzyme activities in mice. As representative enzymes, mediating lipid biogenesis and lipid degradation, the activities of FAS, HMG-CoA reductase and CPT were assessed to investigate whether RFex is able to affect the enzyme activities of lipid metabolism in the liver (Fig. 6). Hepatic FAS and HMG-CoA reductase activity was significantly decreased $(\mathrm{P}<0.05$ each), whereas CPT activity was increased in the RFex-fed group compared with the HFD-fed group $(\mathrm{P}<0.01)$.

\section{Discussion}

Hepatic steatosis is emerging as the most important cause of chronic liver disease associated with the increasing incidence of obesity (9).

It is able to progress to nonalcoholic steatohepatitis in $10-20 \%$ of patients (26) and even to advanced cirrhosis and hepatocellular carcinoma (27). The present study demonstrated that the administration of RFex protected against the 
A

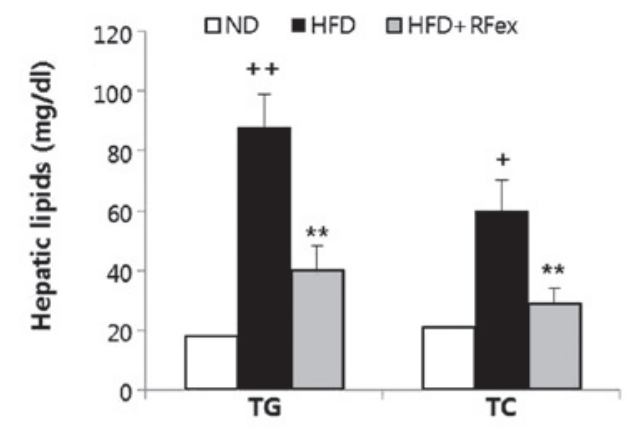

B

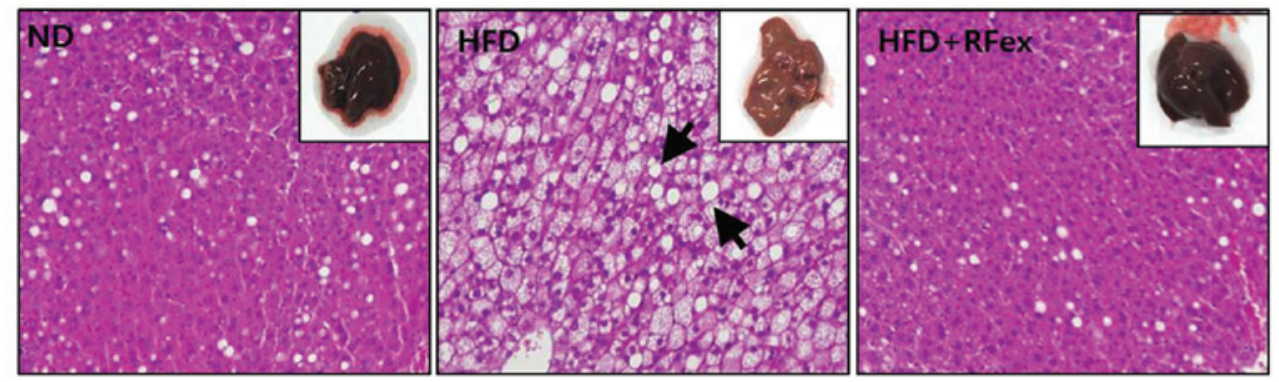

Figure 3. (A) Hepatic TG and TC levels and (B) representative photomicrograph of fatty acid in C57BL/6 mice with an ND, HFD or HFD + RFex. Values are expressed as the mean \pm standard deviation ( $\mathrm{n}=6$ per group). ${ }^{+} \mathrm{P}<0.01,{ }^{++} \mathrm{P}<0.05$ compared with the control (ND). ${ }^{* *} \mathrm{P}<0.01$ compared with the HFD treatment. Arrows indicate the microvesicular-type fat in the cytoplasm of the hepatocytes. TG, triglyceride; TC, total cholesterol ND, normal diet; HFD, high-fat diet; RFex, Rubi Fructus extract.

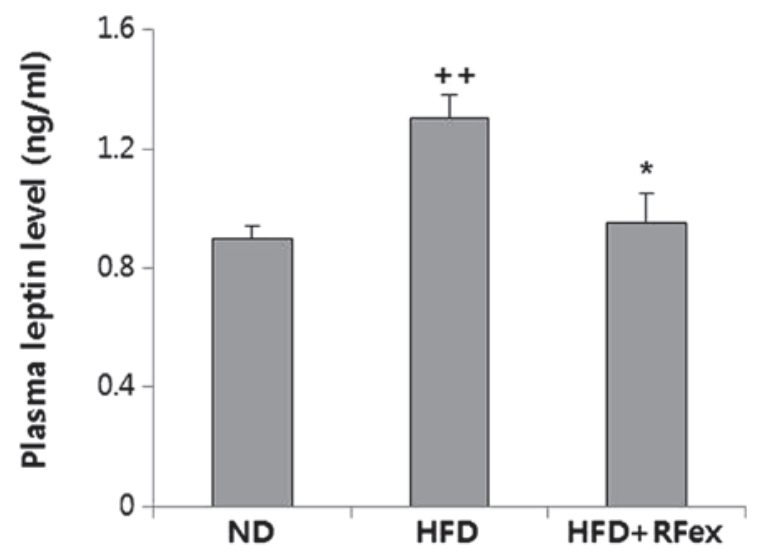

Figure 4. Plasma leptin levels in C57BL/6 mice treated with an ND, HFD and HFD + RFex. Each value represents the mean \pm standard deviation of six mice. ${ }^{++} \mathrm{P}<0.01$ compared with the control (ND) and ${ }^{*} \mathrm{P}<0.05$ compared with HFD treatment. ND, normal diet; HFD, high-fat diet; RFex, Rubi Fructus extract.

development and progression of hepatic steatosis induced by a HFD in C57BL/6 mice. Furthermore, the reduction in levels of hepatic lipids (TG and TC) and plasma lipids (TG, TC and LDL-C) and the elevation of plasma lipid (HDL-C) and leptin levels were observed in RFex-treated C57BL/6 mice. The inhibitory effect of RFex on hepatic steatosis appeared to be associated with the suppression of lipogenesis enzyme activity and the acceleration of fatty acid oxidation in HFD-fed mice. However, the other possible mechanisms underlying the effect of RFex on hepatic steatosis, including intestinal lipid absorption, pancreatic lipase activity and the modulation of fecal sterol excretion by RFex treatment requires to be further investigated. A significant reduction in body weight was observed in the HFD + RFex groups compared with the HFD-fed group (Fig. 1A), although the amount of food consumption was similar between the groups (data not shown). These results suggested that suppressed lipid production and increased energy expenditure were involved in preventing hepatic steatosis in RFex-fed mice.

To further investigate the reduced hepatic lipid production in RFex-fed mice, the mRNA expression levels of lipogenic and lipid-regulating enzymes, including SREBP-1c, FAS, LXR, ACC1, LPL and CD36, were examined using qPCR. LXR is a member of a nuclear receptor superfamily that regulates the expression of key proteins involved in lipid metabolism and inflammation, serving as a type of nuclear cholesterol sensor (28).

LXR also increases the expression of SREBP-1c, which leads to increased hepatic TG synthesis. The present study demonstrated that LXR expression was decreased in RFex-fed mice. SREBP-1c is a key transcription factor regulating the expression of enzymes involved in lipogenesis and fatty acid desaturation as well as in response to fat and insulin (29). Its expression was significantly higher in NAFLD, which was almost 5-fold greater than that in the controls. SREBP-1c is positively regulated by insulin signaling pathways, including insulin receptor substrates 1 and 2. It is known that SREBP-1c is negatively regulated by AMP-activated protein kinase (30). In NAFLD, insulin signaling via insulin receptor substrate 1 causes the upregulation of SREBP1-c, leading to an increased synthesis of fatty acids by the hepatocytes (30).

In the present study, a significant suppression of SREBP-1c and LXR mRNA by RFex was confirmed, which in turn may be expected to lead to the downregulation of lipogenic genes, 
A
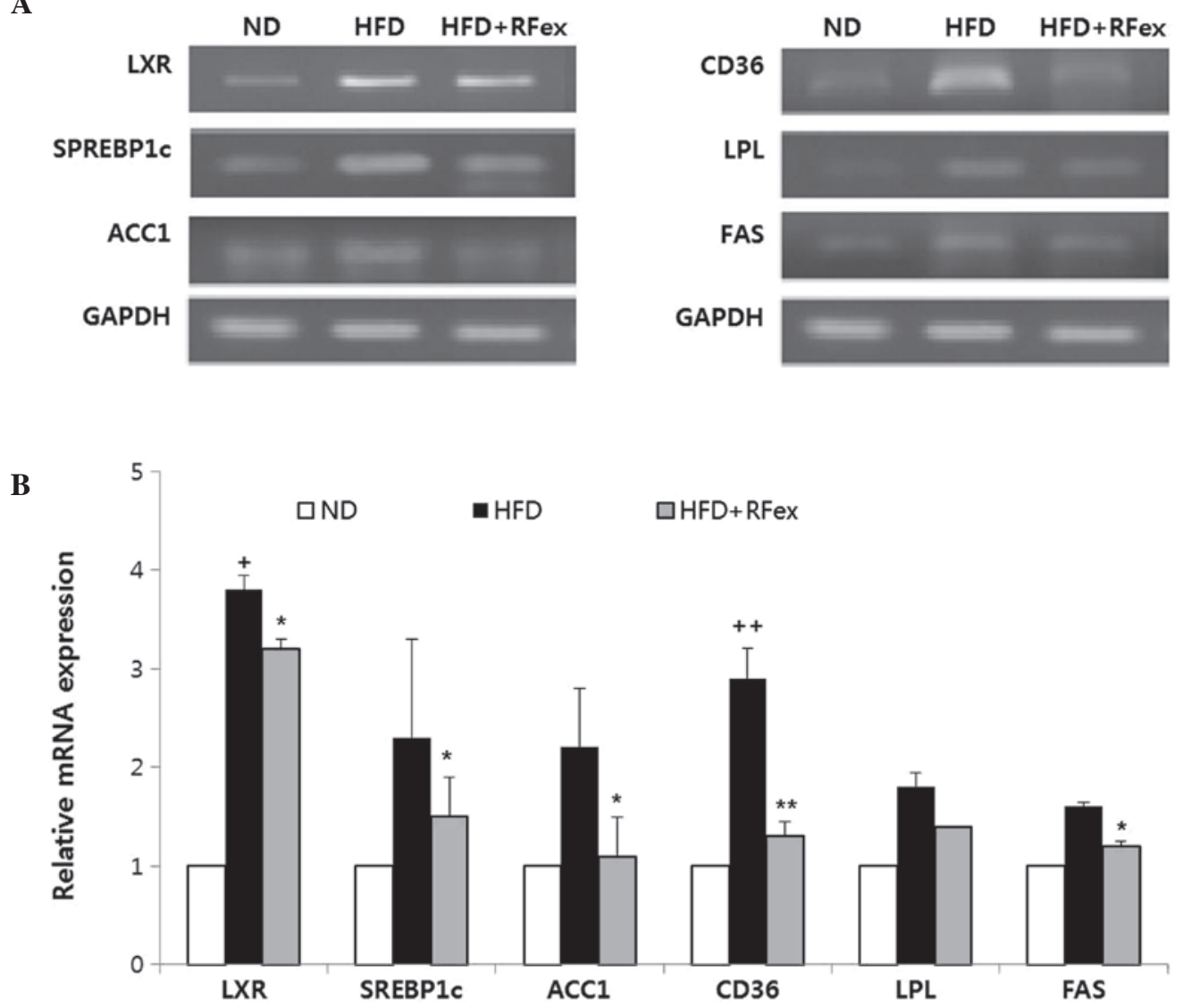

Figure 5. Hepatic expression of lipogenic genes in C57BL/6 mice. (A) Quantitative polymerase chain reaction was used to assess mRNA expression of lipogenic genes using primers as indicated in Table I. (B) Relative levels of specific mRNA levels are presented. Values are expressed as the mean \pm standard deviation ( $\mathrm{n}=6$ each group). ${ }^{+} \mathrm{P}<0.01$ and ${ }^{++} \mathrm{P}<0.05$ compared with the control (ND). ${ }^{*} \mathrm{P}<0.05$ and ${ }^{* *} \mathrm{P}<0.01$ compared with HFD treatment. LXR, liver X receptor; SREBP-1c, sterol regulatory element binding protein-lc; ACC, acetyl Co-A carboxylase; CD36, cluster of differentiation 36; LPL, lipoprotein lipase; FAS, fatty acyl synthase; ND, normal diet; HFD, high-fat diet.

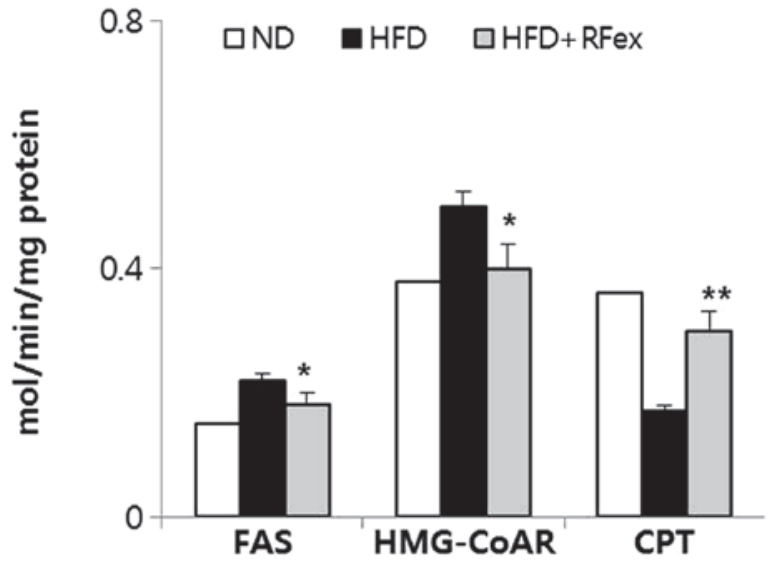

Figure 6. Activity of hepatic lipid regulating enzymes FAS, CPT and HMG-CoAR in C57BL/6 mice treated with ND, HFD and HFD + RFex. Values are expressed as the mean \pm standard deviation ( $n=6$ per group). ${ }^{+} \mathrm{P}<0.01$ compared with the control (ND). ${ }^{*} \mathrm{P}<0.05$ and ${ }^{* *} \mathrm{P}<0.01$ compared with HFD treatment. FAS, fatty acid synthase; CPT, carnitine palmito-transferase; HMG-CoAR, 3-hydroxy-3 methylglutamyl-coenzyme reductase; ND, normal diet; HFD, high-fat diet; RFex, Rubi Fructus extract.

including FAS and ACC. The present study also confirmed the downregulation of FAS and ACC, which are involved in fatty acid biosynthesis, in the RFex-fed group.
The expression levels of LPL and CD36 genes were also assessed. LPL hydrolyzes TG in lipoproteins (chylomicrons and very low density lipoproteins) and is also involved in promoting the cellular uptake of chylomicron remnants, including cholesterol-rich lipoproteins and very low-density lipoprotein. CD36, identified on numerous types of cell surfaces, acts as a fatty acid translocase. The present study demonstrated that LPL and CD36 mRNA expression levels were decreased in RFex-fed groups.

Three enzyme activities, HMG-CoA reductase, FAS and $\mathrm{CPT}$, which are involved in hepatic lipogenesis and lipolytic reactions, were measured. HMG-CoA reductase, an enzyme important in cholesterol synthesis, catalyzes the reduction of HMG-CoA to CoA and mevalonate. The experimental results demonstrated a significant decrease in HMG-CoA reductase and FAS activities in RFex-fed mice. By contrast, the hepatic activity of CPT, an enzyme involved in fatty acid $\beta$-oxidation was increased in RFex-fed mice.

Bioassay-guided fractionation of the methanol extract of Geum japonicum Thunb using a FAS inhibition assay led to the isolation of ellagic acid with six other known compounds (31). Several studies also demonstrated that ellagic acid is involved in lipid metabolism (32). Yu et al (33) have reported that ellagic acid supplementation effectively reduced the elevation of plasma cholesterol in hyperlipidemic rabbits. The exact 
mechanism by which ellagic acid lowers other lipid levels is not known. However, it is likely that ellagic acid may have decreased the activity of HMG CoA reductase or enhanced the rate of lipid degradative processes and increased the hepatic bile acids and fecal neutral sterol, and thus decreased the levels of other lipids.

In conclusion, the present study demonstrated that RFex inhibits hepatic steatosis and has plasma lipid-lowering effects in HFD-fed C57BL/6 mice. These effects are mediated by the downregulation of hepatic genes involved in lipogenesis and the modulation of lipid metabolism-associated enzyme activities.

These results suggested that RFex is useful as a potential dietary food supplement for intervention in hepatic steatosis and hyperlipidemia.

\section{Acknowledgements}

This study was financially supported by the Ministry of Trade Industry and Energy (MOTIE) and the Korea institute for advancement of Technology (KIAT) through the Promoting Regional Specialized Industry Project.

\section{References}

1. Marchesini G, Bugianesi E, Forlani G, Cerrelli F, Lenzi M, Manini R, Natale S, Vanni E, Villanova N, Melchionda N and Rizzetto M: Nonalcoholic fatty liver, steatohepatitis, and the metabolic syndrome. Hepatology 37: 917-923, 2003.

2. Schreuder TC, Verwer BJ, van Nieuwkerk CM and Mulder CJ: Nonalcoholic fatty liver disease: an overview of current insights in pathogenesis, diagnosis and treatment. World J Gastroenterol 14: 2474-2486, 2008.

3. Kotronen A and Yki-Järvinen H: Fatty liver: a novel component of the metabolic syndrome. Arterioscler Thromb Vasc Biol 28 $27-38,2008$

4. Edmison J and McCullough AJ: Pathogenesis of non-alcoholic steatohepatitis: human data. Clin Liver Dis 11: 75-104, 2007.

5. Marchesini G, Brizi M, Bianchi G, Tomassetti S, Bugianesi E, Lenzi M, McCullough AJ, Natale S, Forlani G and Melchionda N Nonalcoholic fatty liver disease: a feature of the metabolic syndrome. Diabetes 50: 1844-1850, 2001.

6. Varela-Rey M, Embade N, Ariz U, Lu SC, Mato JM and Martinez-Chantar ML: Non-alcoholic steatohepatitis and animal models: understanding the human disease. Int J Biochem Cell Biol 41: 969-976, 2009.

7. Nepokroeff CM, Lakshmanan MR and Porter JW: Fatty-acid synthase from rat liver. Methods Enzymol 35: 37-44, 1975

8. Targher G, Bertolini I, Rodella S, Zoppini G, Lippi G, Day C and Muggeo M: Non-alcoholic fatty liver disease is independently associated with an increased prevalence of chronic kidney disease and proliferative/laser-treated retinopathy in type 2 diabetic patients. Diabetologia 51: 444-450, 2008.

9. Unger RH, Clark GO, Scherer PE and Orci L: Lipid homeostasis, lipotoxicity and the metabolic syndrome. Biochim Biophys Acta 1801: 209-214, 2010.

10. Lindor KD, Kowdley KV, Heathcote EJ, Harrison ME, Jorgensen R, Angulo P, Lymp JF, Burgart L and Colin P: Ursodeoxycholic acid for treatment of nonalcoholic steatosis steatohepatitis: results of a randomized trial. Hepatology 39: 770-778, 2004.

11. Sgro C and Escousse A: Side effects of fibrates (except liver and muscle). Therapie 46: 351-354, 1991 (In French).

12. Cha HW, Park MS and Park KM: Physiological activities of Rubus coreanus Miquel. Korean J Food Sci Tech 33: 409-415, 2001.
13. Yang HM, Oh SM, Lim SS, Shin HK, Oh YS and Kim JK: Antiinflammatory activities of Rubus coreanus depend on the degree of fruit ripening. Phytother Res 22: 102-107, 2008.

14. Oh MS, Yang WM, Chang MS, Park W, Kim do R, Lee HK, Kim WN and Park SK: Effect of Rubus coreanus on sperm parameters and cAMP responsive element modulator (CREM) expression in rat testes. J Ethnopharmacol 114: 463-467, 2007.

15. Lee MW: Phenolic compounds from the leaves of Rubus coreanus. Yakhak Hoeji 39: 200-204, 1995.

16. Perry LM: Medicinal plants of east and southeast Asia, attributed properties and uses. MIT press, Cambridge, MA, pp346-356, 1980.

17. Sohn DW, Kim HY, Kim SD, Lee EJ, Kim HS, Kim JK, Hwang SY, Cho YH and Kim SW: Elevation of intracavernous pressure and NO-cGMP activity by a new herbal formula in penile tissues of spontaneous hypertensive male rats. J Ethnopharmacol 120: 176-180, 2008.

18. Lee YI, Choi SK, Yang JY, Cho JS and Kim TH: Hepatoprotective activities of Rubus coreanus depends on the degree of ripening. Natural Product Sciences 15: 156-161, 2009.

19. Lee YI, Whang KE, Cho JS, Ahn BM, Lee SB, Dong MS and Kim TH: Rubus coreanus extract attenuates acetaminophen induced hepatotoxicity; involvement of cytochrome P450 3A4. Biomol Ther 17: 455-460, 2009.

20. Hwang JM, Cho JS, Kim TH and Lee YI: Ellagic acid protects hepatocytes from damage by inhibiting mitochondrial production of reactive oxygen species. Biomed Pharmacother 64: 264-270, 2010.

21. Kang EH, Kown TY, Oh GT, Park WF, Park SI, Park SK and Lee YI: The flavonoid ellagic acid from a medicinal herb inhibits host immune tolerance induced by the hepatitis $\mathrm{B}$ virus-e antigen. Antiviral Res 72: 100-106, 2006.

22. Kaul A and Khanduja KL: Plant polyphenols inhibit benzoyl peroxide-induced superoxide anion radical production and diacylglyceride formation in murine peritoneal macrophages. Nutr Cancer 35: 207-211, 1999.

23. Folch J, Lees M and Sloane Stanley GH: A simple method for the isolation and purification of total lipids from animal tissues. J Biol Chem 226: 497-509, 1957.

24. Hulcher FH and Oleson WH: Simplified spectrophotometric assay for microsomal 3-hydroxy-3-methylglutaryl CoA reductase by measurement of coenzyme A. J Lipid Res 14: 625-631, 1973

25. Markwell MA, McGroarty EJ, Bieber LL and Tolbert NE: The subcellular distribution of carnitine acyltransferases in mammalian liver and kidney. J Biol Chem 248: 3426-3432, 1973.

26. Angulo P: Nonalcoholic fatty liver disease. N Eng J Med 346: 1221-1231, 2002.

27. Dixon JB, Bhathal PS and O'Brien PE: Nonalcoholic fatty liver disease: predictors of nonalcoholic steatohepatitis and liver fibrosis in the severely obese. Gastroenterology 121: 91-100, 2001.

28. Zelcer $\mathrm{N}$ and Tontonoz P: Liver X receptors as integrators of metabolic and inflammatory signaling. J Clin Invest 116: 607-614, 2006.

29. Horton JD, Goldstein JL and Brown MS: SREBPs: Activators of the complete program of cholesterol and fatty acid synthesis in the liver. J Clin Invest 109: 1125-1131, 2002.

30. Zhou G, Myers R, Li Y, Chen Y, Shen X, Fenyk-Melody J, Wu M, Ventre J, Doebber T, Fujii N, Musi N, Hirshman MF, Goodyear LJ and Moller DE: Role of AMP-activated protein kinase in mechanism of metformin action. J Clin Invest 108: 1167-1174, 2001

31. Liu H, Li J, Zhao W, Bao L, Song X, Xia Y, Wang X, Zhang C, Wang X, Yao X and Li M: Fatty acid synthase inhibitors from Geum japonicum Thunb. var. chinense. Chem Biodivers 6: 402-410, 2009.

32. Meyer AS, Heinonen M and Frankel EN: Antioxidant interactions of catechin, cyanidin, caffeic acid, quercetin and ellagic acid on human LDL oxidation. Food Chem 61: 71-75, 1998.

33. Yu YM, Chang WC, Wu CH and Chiang SY: Reduction of oxidative stress and apoptosis in hyperlipidemic rabbits by ellagic acid. J Nutr Biochem 16: 675-681, 2005. 